\title{
A Downscaling Approach Toward High-Resolution Surface Mass Balance Over Antarctica
}

\author{
Hubert Gallée • Cécile Agosta • Luc Gential • Vincent Favier • \\ Gerhard Krinner
}

Received: 29 October 2010/Accepted: 19 April 2011/Published online: 28 May 2011

(C) Springer Science+Business Media B.V. 2011

\begin{abstract}
The Antarctic ice sheet surface mass balance shows high spatial variability over the coastal area. As state-of-the-art climate models usually require coarse resolutions to keep computational costs to a moderate level, they miss some local features that can be captured by field measurements. The downscaling approach adopted here consists of using a cascade of atmospheric models from large scale to meso- $\gamma$ scale. A regional climate model (Modèle Atmosphérique Régional) forced by meteorological reanalyses provides a diagnostic physically-based rain- and snowfall downscaling model with meteorological fields at the regional scale. Although the parameterizations invoked by the downscaling model are fairly simple, the knowledge of small-scale topography significantly improves the representation of spatial variability of precipitation and therefore that of the surface mass balance. Model evaluation is carried out with the help of shallow firn cores and snow height measurements provided by automatic weather stations. Although downscaling of blowing snow still needs to be implemented in the model, the net accumulation gradient across Law Dome summit is shown to be induced mostly by orographic effects on precipitation.
\end{abstract}

Keywords Net accumulation · Downscaling · Antarctica $\cdot$ Law Dome

\section{Introduction}

Sea level rise is identified as one of the major impacts of climate change on populations. Changes in snow mass balance of polar ice sheets directly impact mean sea level through water budget of the Earth system.

Surface mass balance of the Antarctic ice sheet is listed in the IPCC WG1 4th assessment report as the only negative contribution to the twenty-first century sea level rise estimates (Meehl et al. 2007). As temperatures remain low, ablation is not expected to increase much nor the precipitation phase to evolve toward rain, whereas precipitation in a

H. Gallée $(\bowtie) \cdot$ C. Agosta · L. Gential · V. Favier · G. Krinner

UJF-Grenoble 1/CNRS, LGGE UMR 5183, 54 rue Molière, BP 96, 38402,

Saint-Martin-d'Hères Cedex, France

e-mail: gallee@1gge.obs.ujf-grenoble.fr 
moister context might increase more significantly (Krinner et al. 2006; Wild et al. 2003). On the other hand there are studies that show that precipitation has not increased in the past 50 years (e.g. Monaghan et al. 2006). To address the question of future evolution of the Antarctic ice sheet mass balance, modeling is a quite unique tool. However, the ability of current climate models to resolve small scale variability of net accumulation is facing the problem of computational costs.

To resolve the "computational cost versus spatial resolution" dilemma, many downscaling techniques have been proposed and used in the past 30 years, especially for hydrological purposes. Some approaches take advantage of the statistical properties of an observation data set of the target field. Others are based on the physics of orographic precipitation key processes which are supposed to govern small-scale variability (e.g. Goyette and Laprise 1996; Kuligowski and Barros 1999). While the former technique is well suited to complex processes in data-rich regions, the latter one is preferable in data-poor regions, especially when some simple physical law can explain most of the spatial features observed. In the case of Antarctica, a large continent with extreme weather, a physically-based downscaling model should improve the performance of cascades of models used to simulate the Antarctic surface mass balance (Bromwich et al. 2004). The small-scale topography is considered as one of the main forcings on accumulation in the coastal area (Goodwin et al. 2003). Consequently one can imagine that better results will be obtained when adding a downscaling model in the models' cascade than working with an atmospheric general circulation model and even a regional model only. Most of the existing physically-based downscaling models are developed on the basis of orographic precipitation modeling. To compute the airflow dynamics induced by the high-resolution topography, most of these models use results of the linear Boussinesq mountain wave theory (e.g. Smith 2002, Funk and Michaelsen 2004) that allows low computational costs. The most sophisticated models introduce time delays for the formation and the advection of hydrometeors. A further review of orographic precipitation models and their characteristics is given in Table 1 of Barstad and Smith (2005).

As coastal regions are those in Antarctica where small-scale orography shows the steepest slopes, they represent an appropriate domain for testing a physically-based precipitation downscaling model, especially since precipitation explains most of the measured net accumulation (Bromwich 1988). In particular, the area of Law Dome (Fig. 1) can be considered as a perfect laboratory for this kind of model validation. Indeed it is a coastal dome which weather is dominated by easterly flow associated with cyclones moving over the ocean. Consequently it is characterized by high accumulation rates on its eastern side and much lower accumulation rates on its western side. As for other east Antarctic coastal areas the fraction of liquid precipitation and runoff is not significant.

The present paper is organized as follows. In a first part we present the method, i.e. the models and data used. Then we share the results of model evaluation and draw some conclusions on the processes involved in coastal net accumulation. At the end, we discuss the results and conclude to the ability of the method to address the question of fine scale surface mass balance.

\section{Methodology}

\subsection{Some Definitions}

Snow accumulation is defined here as the sum of solid precipitation Ps and the result of the competition between blown snow particles deposition $\mathrm{D}$ and erosion $\mathrm{E}$ by the wind: 


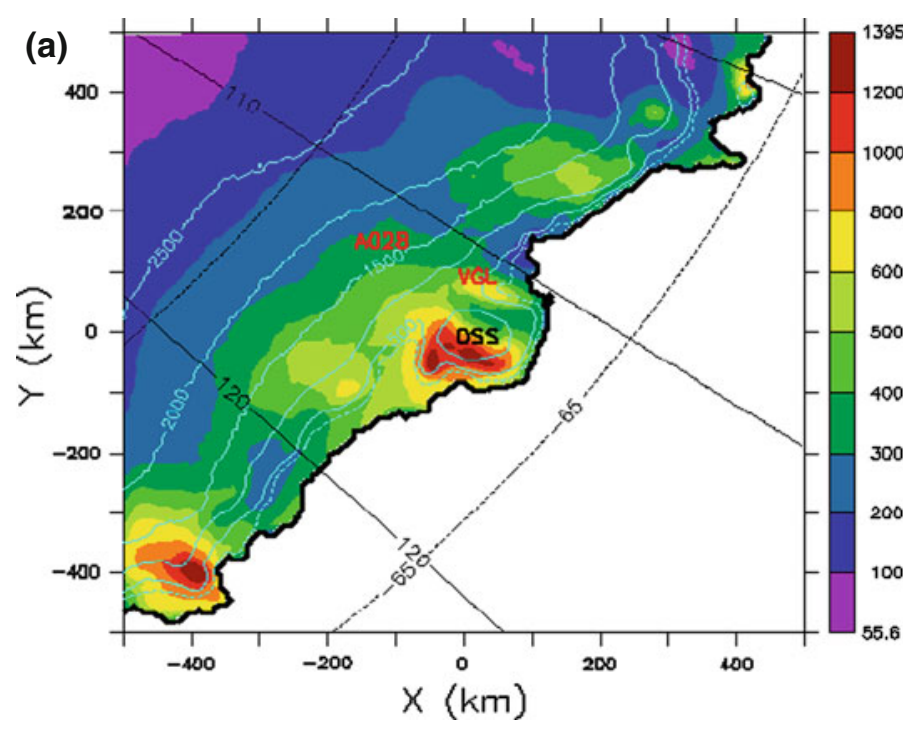

(b)

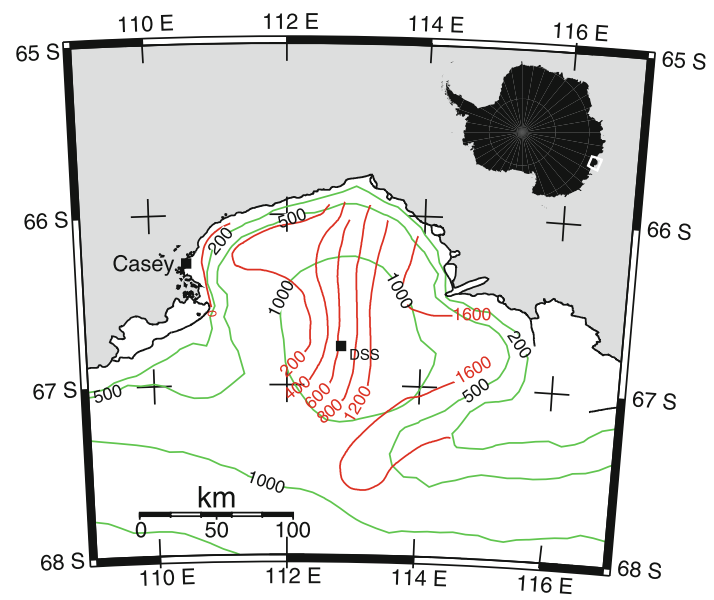

Fig. 1 a Annual-mean SMB over Law Dome area, for the 1998-2001 period (mm w.e. per year, see color scale). Dashed (solid) lines correspond to latitude (longitude E) contours and are drawn every 5 (10) degrees. The 200 (dashed), 500, 1,000, 1,500, 2,000 and 2,500 m surface elevation contours are shown in cyan. VGL Vanderford Glacier, DSS DSS AWS, A028 A028 AWS. b SMB reconstruction over Law Dome made by van Ommen et al. (2004). Red contours: SMB (mm w.e. year $\left.{ }^{-1}\right)$. Green contours: surface elevation (m). Adaptation by van de Berg et al. (2006). Copyright American Geophysical Union. Reproduced by permission of American Geophysical Union

$$
\text { Snow accumulation }=(\mathrm{Ps}+(\mathrm{D}-\mathrm{E})),
$$

Surface mass balance (or net accumulation of snow/ice; hereinafter referred to as SMB) can be expressed as the balance between accumulation and ablation terms as follows:

$$
\text { Surface mass balance SMB }=(\mathrm{Ps}+\mathrm{P} 1+(\mathrm{D}-\mathrm{E})-\mathrm{Su}-\mathrm{R}),
$$

with Pl, Su and R denoting, respectively, liquid precipitation, sublimation and runoff. Units of these quantities are $\mathrm{kg} \mathrm{m}^{-2}$ year $^{-1}$ or $\mathrm{mm}$ water equivalent (mm w.e.) per year. 


\subsection{Model Description}

Downscaling of precipitation was obtained with the use of a diagnostic model that computes total precipitation (solid plus liquid) on a fine grid given fine scale topography and large scale three-dimensional meteorological fields, i.e. pressure, temperature, wind, specific humidity, total water mixing ratio and total precipitation. The physics is based on the upslope model of Sinclair (1994) who assumes that the horizontal wind is not influenced by fine scale topography. The vertical wind component $\mathrm{w}_{\mathrm{s}}$ at the surface is adjusted so that the surface wind vector follows the topography:

$$
\mathrm{w}_{\mathrm{s}}=\mathbf{V}_{\mathrm{s}} \cdot \nabla \mathrm{z}_{\mathrm{s}}
$$

where $\mathbf{V}_{\mathbf{s}}$ is the horizontal component of the wind near the surface and $\nabla z_{s}$ is the surface slope. In Sinclair (1994) the vertical motion decreases with height at a specific rate. Here the importance of vertical stability over Antarctica is taken into account by replacing the initial empirical parameterization of Sinclair (1994) with a more explicit formulation based on the two-dimensional model of linearized internal gravity waves and proposed by Funk and Michaelsen (2004). Furthermore the vertical velocity near the surface is modified in order to take into account the vertical velocity provided by the host model and the influence of its topography on it, as in Goyette and Laprise (1996):

$$
\mathrm{w}_{\mathrm{s}}=\mathrm{w}_{\mathrm{sL}}+\mathbf{V}_{\mathrm{sL}} \cdot \nabla\left(\mathrm{z}_{\mathrm{s}}-\mathrm{z}_{\mathrm{sL}}\right)
$$

where $\mathrm{w}_{\mathrm{sL}}, \mathbf{V}_{\mathrm{sL}}$, and $\mathrm{z}_{\mathrm{sL}}$ are provided by the host model and describe, respectively, its vertical and horizontal velocity, and its topography. Finally, we consider the case of a saturated baroclinic atmosphere when calculating the Scorer parameter (Durran and Klemp 1982). The Scorer parameter is obtained from the linear theory of mountain waves and describes the vertical wave number of lee waves induced by a single ridge.

Condensation occurs when adiabatic cooling of the rising water vapor leads to saturation (i.e. at the LCL-Lifting Condensation Level). Condensation rate above the LCL is calculated assuming that condensation arises by means of saturated ascent along the moist adiabatic. Unsaturated ambient conditions above the LCL are taken into account by multiplying the condensation factor by

$$
\lambda(\mathrm{p})=[(\mathrm{r}(\mathrm{p})-0.6) / 0.4]^{0.5}
$$

where $r(p)$ is the relative humidity and $p$ is the pressure. $\lambda(p)$ is set equal to 0 when $r(p)$ is smaller than 0.6.

Precipitation is then obtained by vertically integrating the condensation rate and by considering the efficiency of precipitation $\lambda_{\mathrm{s}}$ as a function of low-level relative humidity near the surface $r_{s}$

$$
\lambda_{\mathrm{s}}=\left[\left(\mathrm{r}_{\mathrm{s}}-0.8\right) / 0.2\right]^{0.25}
$$

$\lambda_{\mathrm{s}}$ is set equal to 0 when $r_{\mathrm{s}}$ is smaller than 0.8 .

Time delays for the formation of hydrometeors and their advection by the horizontal wind are considered, as well as fall speed of raindrops and snow particles, set to a constant value of 5 and $1 \mathrm{~m} \mathrm{~s}^{-1}$, respectively, as in Collier (1975). We pay attention to the surface boundary condition and calculate a fictive surface horizontal wind speed extrapolated from two levels located above the katabatic layer (approximately 200 and 1,500 m a.g.1.- above ground level). 
The Sinclair (1994) version of the model has been validated over the Alps by Brasseur et al. (2002) who found that such a simple model was able to improve the agreement between rain gauges and the $40-\mathrm{km}$ resolution regional climate model MAR (Modèle Atmosphérique Régional) outputs.

\subsection{Model Setup}

\subsubsection{Spatial and Temporal Domains}

The downscaling model is run over a $1,000 \mathrm{~km} \times 1,000 \mathrm{~km}$ domain centered over Law Dome and covering part of East Antarctica (Fig. 1). This region is chosen because of the supposed role of the orographic forcing on precipitation, the presence of high accumulation rates in the area and the availability of field data.

The 1998-2001 period is justified by the availability of AWS snow height measurements. We claim that 4 years are sufficient to address the climatological signature of the model, although measured annual-mean ENSO index is characterized during this period by near-neutral values (1998 and 2001) and moderately positive values (1999 and 2000). This leads to a wet anomaly of precipitation over Wilkes Land (Guo et al. 2004).

Note that the choice of horizontal domain size has very little influence on the results because the variables of the downscaling model do not depend on the horizontal distances.

\subsubsection{Forcing}

Model synopsis. Our downscaling model is forced every simulated $6 \mathrm{~h}$ by outputs from the regional climate model MAR, described in Gallée and Schayes (1994). MAR has been designed for polar studies and validated over Wilkes Land (Gallée et al. 2005) at the resolution of $40 \mathrm{~km}$ that was also used in the present study. The atmospheric part of MAR is coupled to a snow model and a parameterization of blowing snow is used. MAR is forced at its lateral boundaries by ECMWF reanalyses ERA-40.

Downscaling of the SMB. We derive two MAR experiments with blowing snow parameterization switched on and off (the last denoted by a « $\left.I_{\text {off }} »\right)$. The first one provided a regional SMB without runoff:

$$
\mathrm{Ps}+\mathrm{P} 1+(\mathrm{D}-\mathrm{E})-\mathrm{Su}
$$

Because runoff is overestimated in this simulation, it is replaced by an ensemble mean of a 1980-1982 MAR computation with a slightly different albedo parameterization (varying with the solar zenithal distance-labeled by a star): $\left.\mathrm{R}\right|_{*}$. This only affects grid points that are located very close to the coast. When blowing snow is activated, precipitating snow Ps can't be distinguished from the contribution of drifting grains D-E within the microphysical scheme of MAR. Therefore, a second experiment is performed by switching off the blowing snow parameterization, in order to provide the downscaling model with the meteorological fields at the regional scale. Downscaled precipitation will be denoted by a $\left.\ll\right|_{\mathrm{d}} \gg:\left.P s\right|_{\mathrm{d}}+\left.P I\right|_{\mathrm{d}}$. Thus $\mathrm{Ps}_{\mathrm{d}}+\mathrm{Pl}_{\mathrm{d}}-\left(\mathrm{Ps}_{\text {off }}+\mathrm{Pl}_{\text {off }}\right)$ represents the effects of fine scale topography on precipitation. Except otherwise stated conservation of water is performed by imposing that domain integral of $\mathrm{Ps}_{\mathrm{d}}+\mathrm{Pll}_{\mathrm{d}}$ is equal to domain integral of $\mathrm{Psl}_{\text {off }}+\mathrm{Pll}_{\text {off }}$.

Combined together, and after remapping $\mathrm{X}$ and $\mathrm{Xl}_{\text {off }}$ fields onto the higher resolution grid using a bilinear interpolation method, the former components yielded a downscaled SMB: 


$$
\mathrm{Ps}+\mathrm{P} 1+(\mathrm{D}-\mathrm{E})+\left[\left.\mathrm{Ps}\right|_{\mathrm{d}}+\left.\mathrm{P} 1\right|_{\mathrm{d}}-\left(\left.\mathrm{Ps}\right|_{\text {off }}+\left.\mathrm{P} 1\right|_{\text {off }}\right)\right]-\mathrm{Su}-\left.\mathrm{R}\right|_{*}
$$

Finally the sensitivity of the MAR to blowing snow at the regional scale (including nonlinear processes) reads:

$$
\text { Ps }+(D-E)-\left.P s\right|_{\text {off }}
$$

\subsubsection{Spatial Resolution}

Spatial resolution of our downscaled SMB is set to $5 \mathrm{~km}$ after verifying the convergence of the downscaling model for horizontal resolutions of 80, 40, 20, 10 and $5 \mathrm{~km}$. The forcing of the downscaling model is obtained from MAR set up with an horizontal resolution of $80-\mathrm{km}$, for the year 1999 . The $2.5 \mathrm{~km}$ solution, while not far from the 5-km solution, exceeded the asymptotic value; this behavior can be explained by the fact that one of our hypotheses is not valid for gravity waves whose horizontal wavelength is less than $6.3 \mathrm{~km}$. Little variation was found between the resolutions of 5 and $10 \mathrm{~km}$, in agreement with van de Berg et al. (2006) who noticed that both orographic and accumulation wavelengths were of the order of $10 \mathrm{~km}$.

\subsection{Field Data}

\subsubsection{Ice Cores}

Figure 1 of van Ommen et al. (2004) was used to evaluate the model time mean spatial variability against observation-based data (see adaptation on Fig. 1b). The map showed actual net accumulation over Law Dome and had been obtained by combining dating constraints with an ice-flow model.

\subsubsection{Automatic Weather Stations}

Two automatic weather stations from the Australian Antarctic Division network (http:// aws.acecrc.org.au) were used to compare local time series of modeled net accumulation with field measurements: DSS $\left(66^{\circ} 46^{\prime} 09^{\prime \prime} \mathrm{S}, 112^{\circ} 48^{\prime} 38^{\prime \prime} \mathrm{E}, 1,376 \mathrm{~m}\right.$ a.s.l. (above see level); date of installation: December 20, 1997), located very close to Law Dome Summit South, and A028-B (68 $24^{\prime} 28^{\prime \prime} \mathrm{S}, 112^{\circ} 13^{\prime} 03^{\prime \prime}$ E, 1,622 m a.s.1.; November 6, 1998), located about $300 \mathrm{~km}$ inland from Law Dome (see location of the AWS on Fig. 1.a).

To help for the comparison, snow heights were converted into their water equivalent using snow densities measured in the subsurface snow near the stations: $423.4 \mathrm{~kg} \mathrm{~m}^{-3}$ for DSS (McMorrow et al. 2001) and $420 \pm 20 \mathrm{~kg} \mathrm{~m}^{-3}$ for A028-B (Goodwin et al. 2003). The choice of a constant value is responsible for an overestimation of snow mass balance during the snow densification process. After interpolating AWS data on the model time axis, we applied to the record data a 10-point (i.e. a 15-h) running-box smoothing to soften these artifacts.

As a resolution of $5 \mathrm{~km}$ is high enough for our purposes (see Sect. 2.3.3), field measurements were simply compared to the SMB calculated at the nearest model grid point. Model (observed) altitudes for DSS and A028-B were 1,280 m (1,376 m) and 1,628 m $(1,622 \mathrm{~m})$, respectively. The largest altitude error was obtained for DSS, although the area experiences gentle slopes. Two-thirds of this error appeared to be inherited from the 1-km resolution version of the Radarsat Antarctic Mapping Project Digital Elevation Model of 
Fig. 2 Components of the SMB shown in Fig. 1 (mm w.e. per year, see color scale). Dashed (solid) lines correspond to latitude (longitude E) contours and are drawn every 5 (10) degrees. The 200 (dashed), 500, $1,000,1,500,2,000$ and 2,500 m surface elevation contours are shown in cyan or in blue. a Accumulation defined as in 2.1 plus the marginal rainfall component. b Sublimation. c Runoff

Liu et al. (2001), whose vertical precision for the steeper ice sheet perimeter was estimated to about $35 \mathrm{~m}$.

\section{Results}

\subsection{Time-Integrated Results}

Annual-mean snow mass balance for the years 1998-2001 is compared in Fig. 1 with observations made by van Ommen et al. (2004). The key features of the spatial variability are well captured by the model chain. Because runoff and sublimation remain low in absolute terms, net accumulation is dominated by the accumulation process (Fig. 2).

The simulated (Fig. 1a) and observation-based (Fig. 1b) (van Ommen et al. 2004) SMB gradients across Law Dome share the same main characteristics: west-east direction, homogeneity along a meridian, value over DSS (634 vs. $630 \mathrm{~mm}$ w.e. per year, respectively). However, the modeled SMB is underestimated on the eastern side (no more than $1,395 \mathrm{~mm}$ w.e. in place of $1,600 \mathrm{~mm}$ w.e.) and overestimated on the western side (no less than $300 \mathrm{~mm}$ w.e. in place of $200 \mathrm{~mm}$ w.e.). More striking discrepancies are the decrease of modeled SMB when approaching the eastern coast and the presence of a local maximum in the western side, over the Vanderford Glacier (Fig. 1a, $x$ and $y=20$ and $80 \mathrm{~km}$, respectively).

\subsection{Time Series at AWS Sites}

More local model versus observations plots are shown in Fig. 3 for the two Australian AWS DSS and A028 (see location on Fig. 1a). Downscaled and observed SMB showed good agreement. Over DSS, where sublimation and runoff are negligible (see Fig. 2b, c) as well as the net effects of snow-drift processes (see Fig. 4a), modeled SMB increases more linearly with time than the observed one even when leaving aside compaction delays that add high-frequency artifacts to AWS series. Note that A028 is located farther inland than DSS, explaining why the net accumulation is much smaller there.

\subsection{On the Origin of a Net Accumulation Gradient Across Law Dome Summit}

Figure 4 shows the respective effects of snow drift and downscaling on modeled accumulation. The latter can be taken as an estimate of the fine scale orographic forcing on precipitation. None of these processes were found to have a significant impact on SMB over DSS. However, they are responsible for accumulation gradients across the summit, respectively, in the NW-SE and ENE-WSW directions. Snow-drift processes represent a difference of $230 \mathrm{~mm}$ w.e. per year within $165 \mathrm{~km}$ whereas fine-scale orography represents a difference of $708 \mathrm{~mm}$ w.e. per year within $73 \mathrm{~km}$. Therefore, based on our model results we argue that the SMB gradient across DSS would be caused primarily by the orographic forcing on precipitation. The direction of the observed gradient is consistent with our conclusion. 

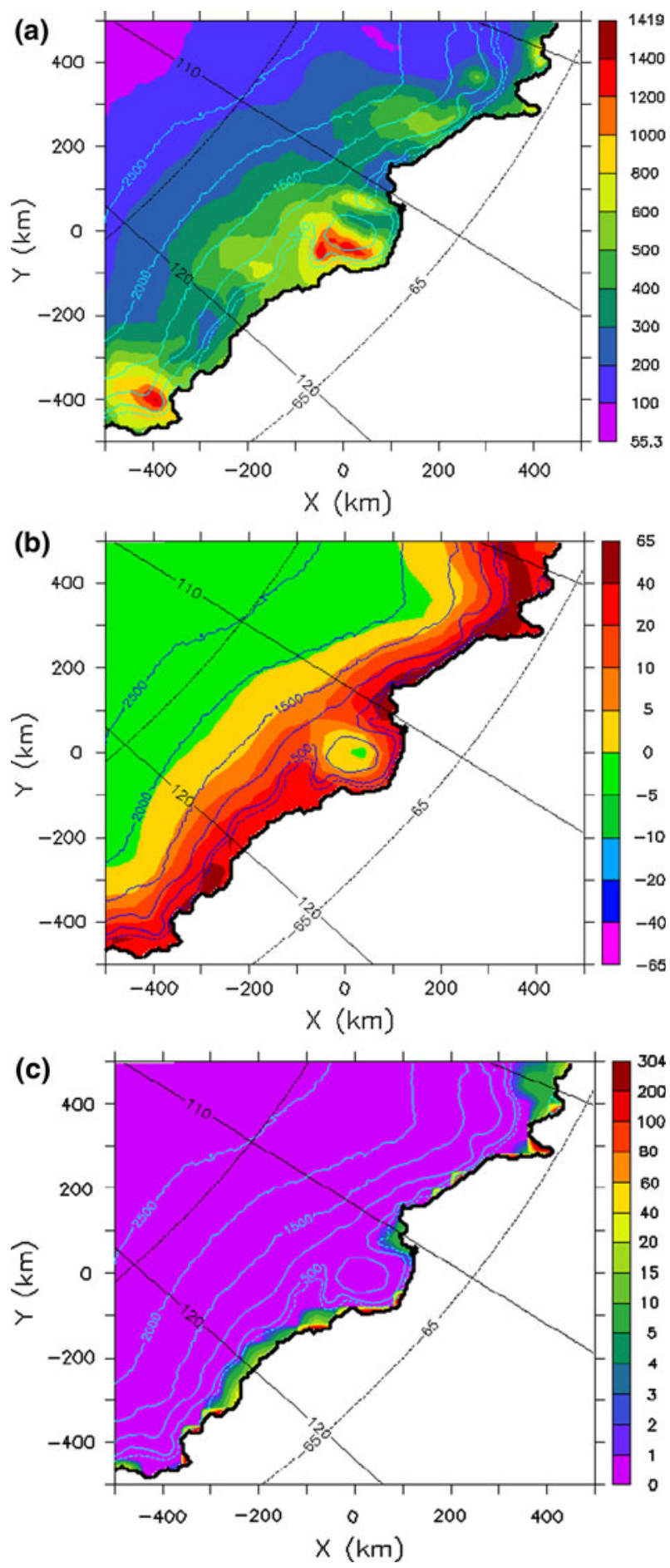


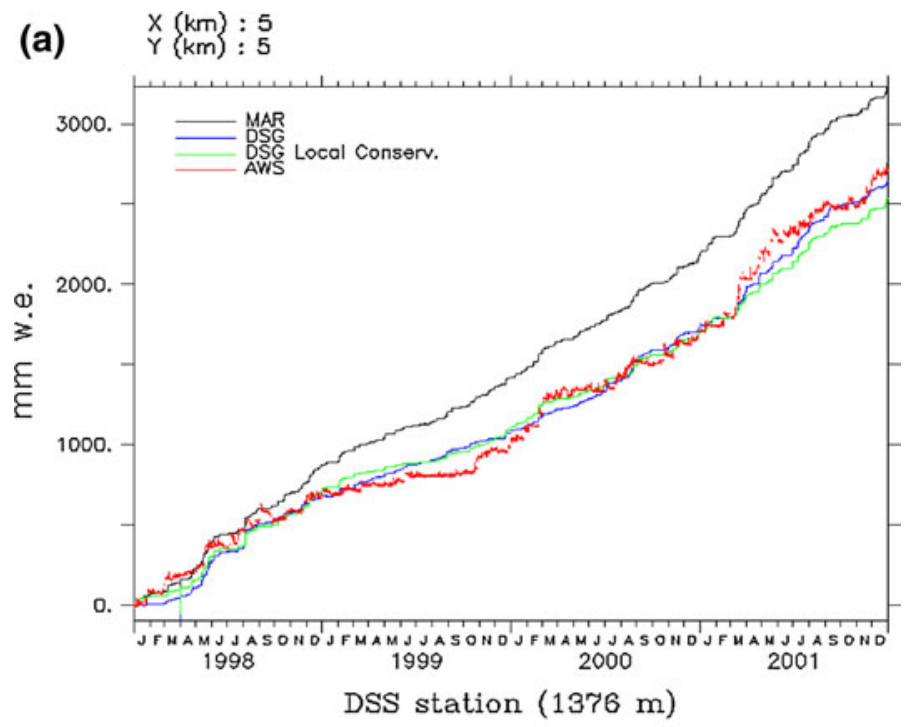

(b) $\quad \begin{aligned} & X \\ & y(k m):-125\end{aligned}$

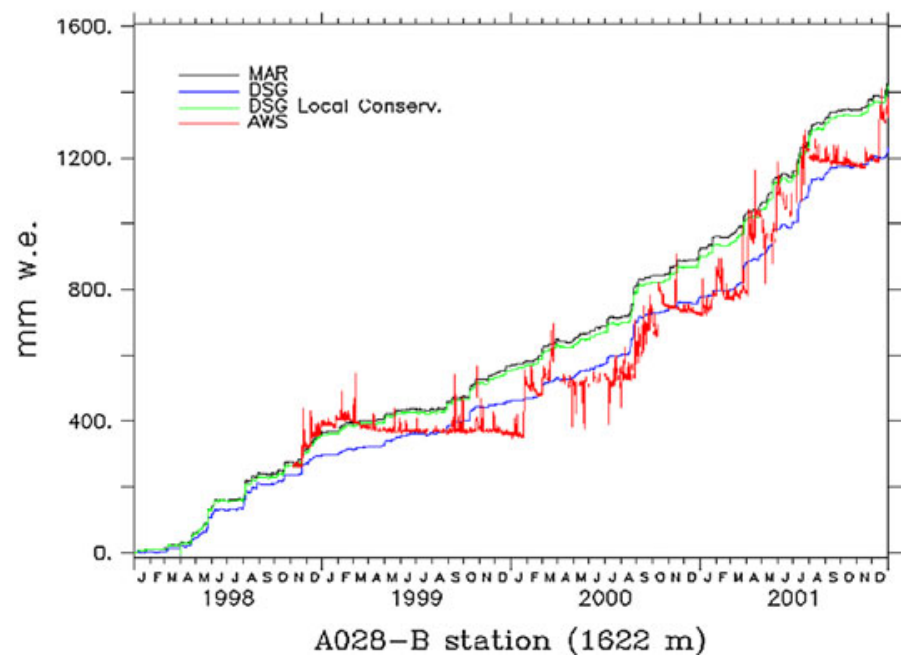

Fig. 3 Surface Mass Balance (mm w.e.): black line: regional climate model MAR; blue line: precipitation downscaled from MAR output (MAR $\rightarrow$ DSG) with domain conservation of water; green line: MAR $\rightarrow$ DSG with local conservation of water; red line: observations made at Automatic Weather Stations. Top panel: DSS; bottom panel: A028-B. Time interval is $6 \mathrm{~h}$

\section{Discussion and Conclusion}

Capturing the small scale features of the surface mass balance becomes of primary importance when directly comparing model data to field measurements. For that purpose, we used a cascade of models from the synoptic scale to the meso- $\gamma$ scale, based on the hypothesis that small scale features of SMB are induced by the orography through upslope 

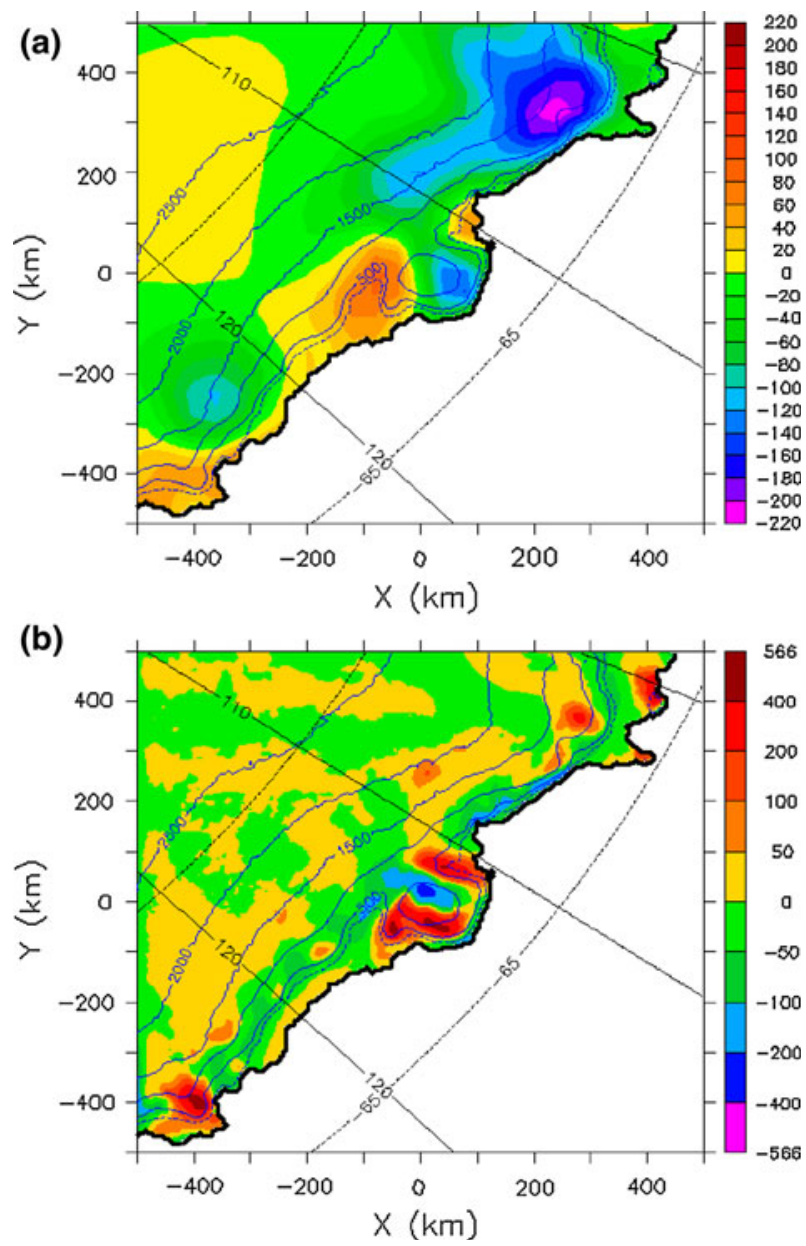

Fig. 4 a Effect of snow drift on accumulation: annual accumulation from the MAR simulation with blowing snow activated, minus annual accumulation from the MAR simulation without blowing snow. b Downscaled precipitation minus MAR precipitation. Unit: $\mathrm{mm}$ w.e. per year (see colour scale). Dashed (solid) lines correspond to latitude (longitude E) contours and are drawn every 5 (10) degrees. The 200 (dashed), 500, 1,000, 1,500, 2,000 and 2,500 $\mathrm{m}$ surface elevation contours are shown in blue

precipitation and snow-drift. Though it kept computational costs within reasonable levels, our method performed quite well when applied to the marked coastal topography of Law Dome. We were able to estimate roughly the roles of the different processes in the repartition of snow among the different slopes. The small scale variations of some SMB components of secondary importance at the regional scale (such as surface sublimation) were neglected in this study, but one should keep in mind that their local variations might be large near the coast (Frezzotti et al. 2004). Therefore, the downscaling of blowing snow, sublimation and melting, and more generally surface energy balance will be implemented in future versions of the downscaling model. The use of a mechanistic downscaling model, as opposed to a statistical one, must be limited to regions in which slopes are steep enough, so that precipitation rates are controlled by orographic processes. Moreover, though the 
Antarctic Peninsula should appear as the ultimate region for downscaling applications, one should first consider implementing a representation of some of the föhn effects, such as lee drying and warming which are thought to be responsible for the lack of stability of the Larsen ice shelf (van den Broeke 2005). Aside from new developments and applications over other regions, downscaling of climatic scenarios will be performed in the frame of the European project ICE2SEA.

Acknowledgments We acknowledge the ice2sea project, funded by the European Commission's 7th Framework Programme through grant number 226375, ice2sea manuscript number 30. The MAR simulations were run on CNRS/IDRIS computers.

\section{References}

Barstad I, Smith RB (2005) Evaluation of orographic precipitation model. J Hydrometeor 6:85-99

Brasseur O, Gallée H, Creutin J-D, Lebel T, Marbaix P (2002) High resolution simulations of precipitation over the Alps with the perspective of coupling to hydrological models. Adv Global Change Res 10:75-100. M. Beniston, Ed

Bromwich DH (1988) Snowfall in high southern latitudes. Rev Geophys 20:149-168

Bromwich DH, Guo Z, Bai L, Chen Q (2004) Modeled antarctic precipitation. Part I: spatial and temporal variability. J Climate 17:427-447

Collier CG (1975) A representation of the effects of topography on surface rainfall within moving baroclinic disturbances. Quart J R Met Soc 101:407-422

Durran DR, Klemp JB (1982) On the effects of moisture on the brunt-Väisälä frequency. J Atmos Sci 39:2152-2158

Frezzotti M, Pourchet M, Flora O, Gandolfi S, Gay M, Urbini S, Vincent C, Becagli S, Gragnani R, Proposito M, Severi M, Traversi R, Udisti R, Fily M (2004) New estimations of precipitation and surface sublimation in East Antarctica from snow accumulation measurements. Clim Dyn 23:803-813

Funk C, Michaelsen J (2004) A simplified diagnostic model of orographic rainfall for enhancing satellitebased rainfall estimates in data-poor regions. J Appl Meteorol 43:1366-1378

Gallée H, Schayes G (1994) Development of a three-dimensional Meso-gamma primitive equation model: katabatic winds simulation in the area of Terra Nova Bay, Antarctica. Mon Weather Rev 122:671-685

Gallée H, Peyaud V, Goodwin I (2005) Simulation of the net snow accumulation along the Wilkes Land transect, Antarctica, with a regional climate model. Ann Glaciol 41:17-22

Goodwin ID, de Angelis M, Pook M, Young NW (2003) Snow accumulation variability in Wilkes Land, East Antarctica, and the relationship to atmospheric ridging in the $130^{\circ}-170^{\circ} \mathrm{E}$ region since 1930 . J Geophys Res 108:4673

Goyette S, Laprise JPR (1996) Numerical investigation with a physically based regional interpolator for off-line downscaling of GCMs: FIZR. J Climate 9:3464-3495

Guo Z, Bromwich DH, Hines KM (2004) Modeled antarctic precipitation. Part II: ENSO modulation over West Antarctica. J Climate 17:448-465

Krinner G, Guicherd B, Ox K, Genthon C, Magand O (2006) Simulated Antarctic precipitation and surface mass balance at the end of the twentieth and twenty-first centuries. Clim Dyn 28:215-230

Kuligowski RJ, Barros AP (1999) High-resolution short-term quantitative precipitation forecasting in mountainous regions using a nested model. J Geophys Res 194:31553-31564

Liu H, Jezek K, Li B, Zhao Z (2001) Radarsat Antarctic Mapping Project digital elevation model version 2. National Snow and Ice Data Center. Digital media, Boulder, CO

McMorrow AJ, Curran MAJ, van Ommen TD, Morgan V, Pook MJ, Allison I (2001) Intercomparison of firn core and meteorological data. Antarct Sci 13:329-337

Meehl GA, Stocker TF, Collins WD, Friedlingstein P, Gaye AT, Gregory JM, Kitoh A, Knutti R, Murphy JM, Noda A, Raper SCB, Watterson IG, Weaver AJ, Zhao Z-C (2007) Global climate projections. In: Solomon S, Qin D, Manning M, Chen Z, Marquis M, Averyt KB, Tignor M, Miller HL (eds) Climate change 2007: the physical science basis. Contribution of working group I to the fourth assessment report of the intergovernmental panel on climate change. Cambridge University Press, Cambridge

Monaghan AJ, Bromwich DH, Fogt RL, Wang S-H, Mayewski PA, Dixon DA, Ekaykin A, Frezzotti M, Goodwin I, Isaksson E, Kaspari SD, Morgan VI, Oerter H, Van Ommen TD, Van der Veen CJ, Wen J (2006) Insignificant change in Antarctic snowfall since the international geophysical year. Science 313(5788):827-831. doi:10.1126/science. 1128243 
Sinclair MR (1994) A diagnostic model for estimating orographic precipitation. J Appl Meteorol $33: 1163-1175$

Smith RB (2002) Stratified airflow over topography. Environmental stratified flows. In: Grimshaw R (ed) Topics in environmental fluid mechanics, vol 3. Kluwer, The Netherlands, pp 119-159

van de Berg WJ, van den Broeke MR, Reijmer CH, van Meijgaard E (2006) Reassessment of the Antarctic surface mass balance using calibrated output of a regional atmospheric climate model. J Geophys Res 111:D11104. doi:10.1029/2005JD006495

van den Broeke M (2005) Strong surface melting preceded collapse of Antarctic Peninsula ice shelf. Geophys Res Lett 32:L12815. doi:10.1029/2005GL023247

van Ommen TD, Morgan V, Curran MAJ (2004) Deglacial and Holocene changes in accumulation at Law Dome, East Antarctica. Ann Glaciol 39:359-365

Wild M, Calanca P, Scherrer SC, Ohmura A (2003) Effects of polar ice sheets on global sea level in highresolution greenhouse scenarios. J Geophys Res 108:4165 